PART 3

Environmental Management 


\title{
Seabird Attraction to Artificial Light in Newfoundland and Labrador's Offshore Oil Fields: Documenting Failed Regulatory Governance
}

\author{
Gail S. Fraser* \\ Faculty of Environmental Studies, York University, Toronto, Ontario, Canada
}

Angela V. Carter

Department of Political Science, University of Waterloo, Waterloo, Ontario, Canada

\section{Introduction}

Seabirds face a wide variety of anthropogenic threats. ${ }^{1}$ Populations exposed to industrial activities causing adult mortality are at risk because their life history strategies (e.g., long-lived, low reproductive rates, and delayed recruitment) ${ }^{2}$ can result in slow recovery or extirpation. ${ }^{3}$ While recent advances in technologies have permitted more detailed information on seabirds as a whole, ${ }^{4}$ this group of organisms is understudied, especially with regard to behaviors and distributions away from breeding sites. ${ }^{5}$

* The authors would like to acknowledge research support from the Social Sciences and Humanities Research Council (865-2008-0062). We thank Janet Russell (Alder Institute), Rachel Bryant, Laurence Packer, and two anonymous reviewers for comments on this article. Email: gsfraser@yorku.ca; angela.carter@uwaterloo.ca.

1 J.P. Croxall et al., "Seabird conservation status, threats and priority actions: A global assessment," Bird Conservation International 22 (2012): 1-34.

2 H. Weimerskirch, "Seabird demography and its relationship with the marine environment," in Biology of Marine Birds, eds. A. Schreiber and J. Burger (Boca Raton: CRC Press, 2001), pp. 115-136; R.D. Wooller et al., "Long-term population studies of seabirds," Trends Ecology and Evolution 7, no. 4 (1992): 111-114.

3 For example, see H.R. Carter et al., "The 1986 Apex Houston oil spill in central California: Seabird injury assessments and litigation process," Marine Ornithology 31 (2003): 9-19.

4 For example, L.A. McFarlane Tranquilla et al., "Multiple colony winter habitat use by Murres (Uria spp.) in the northwest Atlantic Ocean: Implications for marine risk assessment," Marine Ecology Progress Series 472 (2013): 287-303.

5 G.J. Robertson et al., "Miniaturized data loggers and computer programming improve seabird risk and damage assessments for marine oil spills in Atlantic Canada," Journal of Ocean Technology 7 , no. 4 (2012): 41-58. 
In this article, we consider an example of an ongoing regulatory failure to appropriately mitigate and monitor risks posed by the offshore oil industry to seabirds in Newfoundland and Labrador (NL). Specifically, this article focuses on the risk of seabird attraction to lights from offshore oil platforms resulting from two sources: continuous lighting required for illumination on the platform and irregularly occurring gas flaring (both will be referred to as artificial lighting). Flares can extend $20-30 \mathrm{~m}$ from flare stacks that are $70-80 \mathrm{~m}$ in height ${ }^{6}$ in an otherwise often dark environment, ${ }^{7}$ although the extent of lighting from flares can be significant even in daylight conditions. ${ }^{8}$ Artificial light from offshore platforms can cause disorientation, collisions with structures, and mortality for some species of seabirds. ${ }^{9}$ The light from flares can exhaust birds as they endlessly circle the flame, which can also incinerate them. ${ }^{10}$ Systematic nighttime visual (not radar) observations on an oil platform that was flaring in the North Sea suggest seabirds exhibit a wide range of responses to light pollution. ${ }^{11}$ Yet, the degree to which varying light intensities or distances

$6 \quad$ Flare flame size and heat intensity are dependent on a number of variables and can vary both within and among projects. S. Casadio et al., "Gas flaring monitoring from space using the ATSR instrument series," Remote Sensing the Environment 116 (2012): 239-249.

F.K. Wiese et al., "Seabirds at risk around offshore oil platforms in the north-west Atlantic," Marine Pollution Bulletin 42, no. 12 (2001): 1285-1290.

8 A flare was observed 25 nautical miles away in daylight on the Grand Banks, Newfoundland and Labrador; see W.A. Montevecchi and C. Burke, Surveys of Marine Birds and Mammals from Offshore Support Vessels and Ships of Opportunity in Newfoundland Waters, Report prepared for Environmental Studies Research Fund Energy Board of Canada (St. John's: Environmental Studies Research Fund Energy Board of Canada, 2004), p. 22.

Wiese et al., n. 7 above; W.A. Montevecchi, "Influences of artificial light on marine birds," in Ecological Consequences of Artificial Night Lighting, eds. C. Rich and T. Longcore (London: Island Press, 2006), pp. 94-113; C.M. Burke et al., "Inadequate environmental monitoring around offshore oil and gas platforms on the Grand Bank of Eastern Canada: Are risks to marine birds known?," Journal of Environmental Management, 104 (2012): 121-126; R.A. Ronconi et al., "Bird interactions with offshore oil and gas platforms: Review of impacts and monitoring techniques," Journal of Environmental Management 147 (2015): 34-45; J.I. Ellis et al., "Mortality of migratory birds from marine commercial fisheries and offshore oil and gas production in Canada," Avian Conservation and Ecology 8, no. 2 (2013): 4-20; G.S. Fraser, "Offshore oil and gas development impacts on marine wildlife resources," in Peak Oil, Economic Growth, and Wildlife Conservation, eds. J.E. Gates et al. (New York: Springer, 2015), pp. 191-217.

$10 \quad$ Wiese et al., n. 7 above. See also D. Wood, "Hibernia," EnRoute Magazine, February (1999): 48-59.

P. Hope-Jones, “The effect on birds of a North Sea gas flare," British Birds 73 (1980):547-555. 
from light sources act as attractants remains unknown; seabird attraction to artificial lighting is an understudied phenomenon.

Environmental regulation, including the protection, monitoring, and mitigation of the industry's impacts on seabirds, involves a complex set of regulations, legislation, and intergovernmental relationships. Outside of oil and gas extraction, the protection of seabirds in Canada falls to a federal agency, Environment Canada. ${ }^{12}$ However, as a result of decades of acrimonious federal-provincial debates about which level of government owned offshore oil resources (and revenues), ${ }^{13}$ the Canada-Newfoundland Atlantic Accord Implementation $\mathrm{Act}^{14}$ initiated regulation of offshore oil and gas activities by the establishment of a joint federal-provincial board. The Canada-Newfoundland and Labrador Offshore Petroleum Board (C-NLOPB) ${ }^{15}$ was tasked with regulating daily operations and enforcing environmental regulatory compliance. ${ }^{16}$ The Canadian Environmental Assessment Act, 1992, also designated the $\mathrm{C}-\mathrm{NLOPB}$ as the lead responsible authority for the environmental assessment (EA) processes. ${ }^{17}$ The creation of the C-NLOPB in 1987 was a remarkable example of environmental regulatory authority devolution in Canada that coincided with a broader federal commitment to foster energy development. ${ }^{18}$

12 Environment Canada is now known as Environment and Climate Change Canada; see also, Environment and Climate Change Canada, "Migratory birds," available online: <https:// www.ec.gc.ca/nature/default.asp?lang=En\&n=FDF836EF-1>.

13 A. Black, "Jurisdiction over petroleum operations in Canada," International and Comparative Law Quarterly 35, no. 1 (1986): 446-456; R. Blake, "Politics and the federal principle in Canada: Newfoundland offshore oil development and the quest for political stability and economic justice," Canadian Historical Review 96, no. 1 (2015): 32-60; C. MacDonald and R.S.G. Thompson, "The Atlantic Accord: The politics of compromise," Alberta Law Review 24 (1986): 61-80.

14 Canada-Newfoundland and Labrador Atlantic Accord Implementation Act, S.C. C.3 (1987) [Atlantic Accord Act].

15 Originally named the Canada-Newfoundland Offshore Petroleum Board (C-NOPB). We will reference either depending on the date of literature cited, but use C-NLOPB in the text.

16 Atlantic Accord Act, n. 14 above; See also G. van Driel and A. McDonald, "Environmental regime for development of an oil and gas project in the Newfoundland offshore," Alberta Law Review 40, no. 1 (2002): 130-164; Erlandson Consulting Inc. and Petroleum Research Atlantic Canada, Offshore Oil and Gas Approvals in Atlantic Canada: A Guide to Regulatory Approval (Ottawa, Halifax, St. John's: Atlantic Energy Roundtable, 2004).

17 Canadian Environmental Assessment Act, S.C. 1992, c. 37, s. 59(i)(v), in accordance with the Atlantic Accord Act, n. 14 above, s. 138.01(1).

18 L. Pratt, "Energy, regionalism and Canadian nationalism," Newfoundland Studies 1, no. 2 (1985): 175-199. 
As a partial corrective measure to the change in environmental regulatory structure, a memorandum of understanding (MOU) ${ }^{19}$ between the C-NLOPB and Environment and Climate Change Canada was created to maintain specific roles and responsibilities for the federal agency, and to provide a governance framework to facilitate cooperation. ${ }^{20}$ In this MOU, Environment Canada was specifically designated as a body that would provide advice on migratory birds and ensure implementation of the Migratory Bird Convention Act. ${ }^{21}$ Moreover, the MOU stated that the C-NLOPB would "take into account the advice of the other Parties [Environment Canada] in developing and reviewing monitoring studies to assess the effects of offshore oil and gas activities on migratory birds and the marine and coastal environments," thus establishing an institutional structure to implement the agreement's stipulations. ${ }^{22}$

\section{Methods}

The objective of this article is to document the decisions and regulations pertaining to the effects of artificial light on seabirds. We reviewed policy documents, guidelines and regulations, environmental assessments and mitigation measures, MOUs, environmental effects monitoring programs, and reports to trace the origins, development, and discussion of mitigation measures for seabird attraction to artificial light from offshore oil production platforms in NL. The majority of documents are available online, except for Environment

19 Canada-Newfoundland and Labrador Offshore Petroleum Board, Memorandum of Understanding Among CNOPB, Environment Canada, Department of Energy, Mines and Resources, the Newfoundland and Labrador Department of Environment and Lands, The Newfoundland and Labrador Department of Energy, The Newfoundland and Labrador Intergovernmental Affairs Secretariat concerning the Provision of Environmental Services in the Newfoundland Offshore Area, 1988 (St. John's: C-NOPB, 1988), p. 19. The 1988 MOU is what was applicable to our study (see below "Methods"). The MOU was updated in 2015. Environment Canada and Canada-Newfoundland and Labrador Offshore Petroleum Board, Memorandum of Understanding between Canada-Newfoundland and Labrador Offshore Petroleum Board and Environment Canada (St. John's: C-NLOPB, 2015), p. 12.

20 While the Atlantic Accord Act, n. 14 above, s. 46(1)(a) included coordination with government departments and agencies, the $1988 \mathrm{MOU}$ identified coordination specific to the environment (C-NOPB et al., n. 19 above, p. 2). The 1988 MOU required the C-NOPB and Environment Canada to "consult each other to ensure that, insofar as it is appropriate, the approach to enforcing environmental legislation affecting oil and gas activities is consistent in Canada's offshore area."

21 van Driel and McDonald, n. 16 above; Migratory Bird Convention Act, S.C. 1994, c. 22.

22 C-NOPB et al., n. 19 above. 
Canada's comments for EAs, which were obtained from the C-NLOPB by request. We also included data received from an Access to Information request made to Environment Canada on operator reports of birds found on the three production platforms from 2000 to 2011 . The request asked for the name of the production operator for each relevant dataset, the name of the platform for each bird collected, the date each bird was collected, the time each bird was collected, the number and species of birds collected per day (or night), the number and species of birds found alive and subsequently released, the number and species of birds found dead, whether the cause of death was recorded, and the weather for each incident (specifically whether moonlight or fog were noted). We compared the information received to the protocol implemented, as well as to the recommendations made by Environment Canada to improve mitigation measures by incorporating systematic monitoring.

\section{Study Area}

As of 2017, oil is produced from three fields in NL's offshore area. The Hibernia Management and Development Company Ltd. began producing oil from the Hibernia field in 1997, Petro-Canada began producing oil from the Terra Nova field in 2002 (operations are now led by Suncor Energy), and Husky Energy began producing oil from the White Rose field in $2005 .{ }^{23} \mathrm{~A}$ fourth project, Hebron, is anticipated to begin production late in $2017 .{ }^{24}$ Each operating project has flare and lighting systems that pose risks to seabirds. ${ }^{25}$

The NL offshore area supports one of the most diverse and abundant seabird communities in the world-an estimated 40 million birds comprising

23 Mobil Oil Canada Limited, Hibernia Development Project, Environmental Impact Statement, Volume IIIB Biophysical Assessment (St. John's: Mobil Oil Canada Limited, July 16, 1985); Petro-Canada, Development Application for Terra Nova Development Environmental Impact Statement (St. John's: Petro-Canada, 1997); Husky Oil Operations Ltd., White Rose Development Environmental Comprehensive Study, Part I (St. John's: Husky Oil Operations Ltd., 200o), available online: <http://www.cnlopb.ca/pdfs/wrda_vol3_vol4.pdf>.

24 ExxonMobil Canada Properties, Hebron Project Final Comprehensive Study Report (St. John's: ExxonMobil Canada Properties, 2011), available online: $<$ http://hebronpublicreview .ca/public-registry-of-documents/>.

25 Each project has a restriction on the amount of gas flaring. For example, Hibernia was permitted to flare 3,833 million standard cubic feet in 2006-2007; Terra Nova was permitted to flare 4,609 million standard cubic feet over January to December 2007; see Canada-Newfoundland and Labrador Offshore Petroleum Board, 2006-2007 Annual Report (St. John's: C-NLOPB 2007), p. 76. However, the C-NLOPB does not restrict when flaring can occur and does not report details on season or time of day of flaring; see Canada-Newfoundland and Labrador Offshore Petroleum Board, 2014-2015 Annual Report (St. John's: C-NLOPB 2015), p. 64. 
twenty species. ${ }^{26}$ Seabirds from the Arctic move to the Grand Banks in winter (e.g., thick-billed murres, Uria lomvia; dovekies, Alle alle) and shearwaters (Puffinus spp.) from the southern hemisphere migrate into the area in the summer months. ${ }^{27}$ This biologically rich region has been the location of offshore oil activity since the 1970s.

Resident Leach's storm petrels (Oceanodroma leucorhoa) ${ }^{28}$ appear to be particularly vulnerable to light attraction, likely due to their foraging on bioluminescent prey. ${ }^{29}$ Leach's storm petrel attraction to artificial light has been known for over one hundred years. ${ }^{30}$ Other species also seem vulnerable to light pollution, based primarily on an anecdotal observation of "thousands of dovekies circling in the Hibernia lights for hours on end." ${ }^{31}$ In NL waters, Ellis et al. estimate seventy-five (median) live birds are recovered per offshore oil platform annually and twelve (median) birds die annually on a total of three platforms due solely to attraction effects. These are underestimates as some birds are not detected (e.g., they fall into the ocean), and more research was recommended to assess total incidental mortality. ${ }^{32}$

\section{The Origins of a Mitigation Measure for Seabird Attraction to Artificial Light}

The EAs for oil production projects-one completed under the Federal Environmental Assessment Review Process (Hibernia 1985) and the remaining

26 A. Lock et al., Gazetteer of Marine Birds in Atlantic Canada (Dartmouth: Canadian Wildlife Service, 1994); R.G. Brown, Revised Atlas of Eastern Canadian Seabirds (Dartmouth: Canadian Wildlife Service, 1986).

27 Lock et al., id.; W.A. Montevecchi and L.M. Tuck, Newfoundland Birds: Exploitation, Study, Conservation (Cambridge, MA: Nuttal Ornithological Club, 1987).

28 Wiese et al., n. 7 above; Montevecchi, n. 9 above.

29 M. Imber, "Behavior of petrels in relation to the moon and artificial lights," Notornis 22, no. 4 (1975): 302-306; C.E. Huntington et al., "Leach's storm-petrel (Oceanodroma leucorhoa)," in The Birds of North America, ed. P.G. Rodewald (Ithaca: Cornell Lab of Ornithology, 1996).

30 G.S. Miller Jr., "Winge on birds at the Danish Lighthouses," Auk 14 (1897): 415-417. Montevecchi and Wiese et al. both provide reviews; n. 9 and n. 7 above.

31 Wiese et al., n. 7 above; see also M.H. Dick and W. Donaldson, "Fishing vessel endangered by crested auklet landings," Condor 80 (1978): 235-236, describing a closely related species being attracted to light on a fishing vessel; M.P. Harris, The Puffin (Calton: T \& AD Poyser, 1984), describing Atlantic Puffin attraction to artificial light.

Ellis et al., n. 9 above. 
under the Canadian Environmental Assessment Act (Terra Nova 1997, White Rose 2000, and Hebron 2011) — all identified marine birds as a major concern. ${ }^{33}$ No mitigation measures were identified for seabird attraction to artificial light in the Hibernia EA. ${ }^{34}$ However, in the three subsequent project EAs, Environment Canada, and the public expressed concerns about seabird mortality due to light attraction and requested mitigation. ${ }^{35}$ In response to these concerns, the Terra Nova Joint Panel Review recommended that "the Board require the Proponents to undertake a study of seabird attraction to, and collisions with, offshore petroleum facilities, and in this effort should seek cooperation with the Hibernia project so that early evaluation of light effects might be possible, and so that there might be opportunity to test any mitigation procedures which might be required." 36 Two public commissioners reviewing the

33 Petro-Canada, Husky Oil Operations Ltd., ExxonMobil Canada Properties, n. 23 and n. 24 above.

34 Mobil Oil Canada, n. 23 above.

35 For the Terra Nova EA, Environment Canada recommended, "The proponent should identify and implement mitigations (e.g., the use of shades on lights and alternative options to open flame flaring, etc.,) with respect to lights and gas flaring to prevent impact on seabirds." See Environment Canada, "Submission to the Joint Public Review, Terra Nova Project" (April 14, 1997), p. 20, Recommendation 25. For the White Rose EA, Environment Canada noted, "The White Rose project is located closer to the edge of the continental shelf and to the Flemish Cap, where there is $[$ sic $]$ no marine bird distribution and abundance data ... Environment Canada strongly recommends that the proponent commit to a monitoring program for marine birds during development and production stages ... the ongoing monitoring program for the Terra Nova project has been successful in producing a database which records the potential for interactions of seabirds with drilling infrastructure. A cooperative effort to update information on the status of regional seabird colonies, including Leach's Storm Petrels and to maintain a database on pops would be highly valuable in documenting and managing environmental impacts." See Environment Canada's submission to the White Rose Oilfield Comprehensive Study, in Husky Oil Operations Limited, White Rose Oilfield Comprehensive Study Supplemental Report, April 2001, p. 240, Comment 189. Environment Canada's comments to the Hebron project are discussed below, see Environment Canada, "Submission to Hebron Development Project Draft CSR, Environment Canada" (August 11, 2010), pp. 29-30. The Natural History Society of Newfoundland and Labrador identified the risks that platform lights and flaring pose to seabirds and requested that independent observers be used to collect environmental data; see Natural History Society of Newfoundland and Labrador, "Submission to Canadian Environmental Assessment Agency" (May 24, 2001).

36 Terra Nova Development Project Environmental Assessment Panel, A Report to the Canadian Environmental Assessment Agency, Canada-Newfoundland Offshore Petroleum Board and The Government of Newfoundland and Labrador (St. John's: Terra Nova Development Project Environmental Assessment Panel Report, August 1997), 
subsequent White Rose and Hebron projects also recommended EA follow-up on this issue. ${ }^{37}$

To date, mitigation measures for seabird attraction to artificial light center on a brief protocol developed in the late 1990s. Environment Canada's Canadian Wildlife Service collaborated with a Petro-Canada representative to develop a protocol to understand and to mitigate the attractant effects from artificial light on seabirds. The protocol, Leach's Storm-petrel: General information and handling instructions, ${ }^{38}$ described storm petrel attraction to light and the potential of birds colliding with the platform, particularly on foggy nights. The protocol primarily provided guidance on how to handle and release stranded birds. It also requested from, and emphasized to, operators the need for data on the conditions (weather, fog, and moonlight) associated with the time and date of bird strandings. ${ }^{39}$ However this protocol had limited utility: it did not require a proper (i.e., repeatable and systematic) monitoring program to permit the assessment of the impact of artificial lighting. Protocols, used

Recommendation 66, quote at p. 58, available online: <http://www.ceaa-acee.gc.ca/ default.asp?lang=En\&xml=804525A3-BECD-47C6-84B1-A5E159125986 >. In response, the C-NOPB stated, "The Board will explore with the Hibernia Management and Development Company and with representatives of the Canadian Wildlife Service of Environment Canada whether the potential attraction of seabirds to lights on offshore platforms may be credibly investigated using existing platform personnel. ... The Board will expect the proponent to participate in these studies as appropriate and to take their results into account in the design of its facilities." See C-NOPB, Decision 97.02 Application for Approval, Terra Nova Canada-Newfoundland Benefits Plan, Terra Nova Development Plan (St. John's: C-NOPB, December, 1997), p. 48.

37 G.S. Fraser and J. Russell, "Following-up on uncertain environmental assessment predictions: The case of offshore oil projects and seabirds off Newfoundland and Labrador," Journal of Environmental Assessment Policy and Management, 18 (2016), doi: <http:// dx.doi.org/10.1142/S1464333216500046>.

38 U. Williams and J. Chardine, Leach's Storm-petrel: General information and handling instructions (St. John's: C-NOPB, 1999), available online: <http://www.cnlopb.ca/pdfs/ whiterose/stormpetmig.pdf >. It has also been cited as U. Williams and J. Chardine, Terra Nova Storm Petrel Mitigation Program (St. John's: C-NOPB, 1999) and U. Williams and J. Chardine, Leach's Storm-petrel (Oceanodroma leucorhoa): A Handbook on Release Techniques Prepared for Workers on the Terra Nova Oil Field (St. John's: C-NOPB, 1999). All three titles refer to the same document.

39 Williams and Chardine emphasized this point as follows: "Someone should be given the responsibility of maintaining a tally of birds that have been captured and released, and those that were found dead on deck. These notes should be kept with other information about the conditions on the night of the incident (moonlight, fog, and weather), date, time, etc. THIS IS A VERY IMPORTANT PART OF THE EXERCISE AS IT IS THE ONLY WAY WE CAN LEARN MORE ABOUT THESE EVENTS" (original emphasis). 
as mitigation tools in EAs, should appropriately match the EA prediction(s) when the expectation of the mitigation measure is to reduce or prevent the effect from occurring. ${ }^{40}$ In this case, the EA predictions used the following metrics: magnitude, geographic extent, frequency, duration, and reversibility of seabird attraction to artificial lights. ${ }^{41}$ Yet the protocol, as implemented, only addressed bird collisions or strandings; it did not seek to prevent attraction to a platform, nor were the data collected used in a way to permit reductions in EA prediction uncertainty. ${ }^{42}$ Despite this, the protocol was applied in both White Rose and Hebron EAs as a project-specific mitigation measure for the effect of seabird attraction to artificial lights. ${ }^{43}$

\section{Application of the Protocol: Environment Canada's Critique and the Permitting Process}

The protocol was researched and developed from 1999 to 2002. During this time, three operators collected data on drilling rigs using the protocol and reported the number of bird strandings (441 stranded bird encounters), the species (seven species, the majority of which were Leach's storm petrels), and associated mortalities (mortality was reported, but not its cause(s)). The protocol efforts were evaluated by Environment Canada in a report in 2005, ${ }^{44}$ wherein Environment Canada representatives noted they were unable to analyze the data for even basic information such as causes of attraction or mortality, or differences among drilling rigs. They recommended the implementation of a systematic seabird monitoring program using trained observers. Such systematic data collection would include recording negative data (i.e., searches which resulted in no birds being observed) and search effort (time and place of searches), along with the information on the number of birds found and the weather conditions in which they were found. Environment Canada noted

40 See A. Tennøy, "Consequences of EIA prediction uncertainty on mitigation, follow-up and post-auditing," in Standards and Thresholds for Impact Assessment, eds. M. Schmidt et al. (Berlin: Springer-Verlag, 2008), pp. 447-46o.

41 Fraser and Russell, n. 37 above; Petro-Canada, n. 23 above; Husky Oil Operations Ltd., n. 23 above.

42 Fraser and Russell, id.

43 Husky Oil Operations Ltd., n. 23 above; ExxonMobil Canada Properties, n. 24 above, pp. 447-46o.

44 S.M. Baillie et al., "Seabird data collected by the Grand Banks offshore hydrocarbon industry 1999-2002: Results, limitations and suggestions for improvement," Canadian Wildlife Service Technical Report Series No. 434, (St. John's: Environment Canada, 2005), p. $5^{2 .}$ 
that this approach is needed "in order to define mechanisms of attraction and to ensure appropriate mitigation procedures are being used." 45 However, Environment Canada's recommendations to the operators were not incorporated into the protocol; ${ }^{46}$ it remained unchanged from its original form in 1999 to the writing of this article in $2017 .{ }^{47}$

Starting in 2003, Environment Canada began issuing annual Federal Migratory Bird Salvage permits to operators, which allowed operators to handle dead or stranded birds on the platforms as part of the protocol. The year the permit was first issued corresponded to the operator's implementation of the protocol (Hibernia and Terra Nova during their post-EA phase and the White Rose, as a project-specific mitigation). While Petro-Canada received its first permit in 2003, Hibernia did not receive a permit until 2005. Husky received a permit in 2006, the year following the start of oil production. The permit required operators to submit a form on an annual basis to Environment Canada.

From our Access to Information request, we received data collected in the research and development phase (1999-2002) and in the Bird Salvage Permit phase (2005-2011) from all three production platforms. The bird salvage forms received and issued by Environment Canada asked for the date of collection, bird species, number recovered on deck, number deceased, number released, number oiled, and comments. The form did not ask for the time a bird was found or the weather, two basic metrics identified as important in the protocol. ${ }^{48}$ Most reports had the specific date a bird was found, the number of birds found on that date, the species, and the fate of each bird (Table 10.1). When a

45 Id. (emphasis added).

46 For examples, see Williams and Chardine, n. 38 above and C-NLOPB, "Project-based environmental assessments: Polarcus UK Ltd. Eastern Newfoundland Offshore $2 \mathrm{D},{ }_{3} \mathrm{D}$ and 4D Seismic Program, 2016 to 2022," available online: <http://www.cnlopb.ca/assessments/ polarcusec.php>.

47 While Husky Oil Operations Ltd. has their own document $(2005,2008)$ providing more background information, chain of command, etc., the protocol within these documents was identical to Williams and Chardine 1999 (as it should be if there is to be any comparison to other platforms), including requests for recording the weather at the time birds were salvaged. See also, Williams and Chardine, n. 38 above.

48 Environment Canada now provides a form that asks for wind direction, sea state, and visibility; for example, see C-NLOPB, "Project-based Environmental Assessments," available online: <http://www.cnlopb.ca/assessments/polarcusec.php>; for an example of a best practices document, see Environment Canada, "Best Practices for Stranded Birds Encountered Offshore Atlantic Canada, Draft 2" (April 17, 2015), available online: <http:www .cnlopb.ca/pdfs/mg3/strandbird.pdf>. 
TABLE 10.1 Operators' data from 2005-2010 compared to the required protocol as implemented as a mitigation measure (top panels) ${ }^{a}$ and to the additional information as part of a monitoring program recommended by Environment Canada in 2005 (bottom panels). ${ }^{b}$

\begin{tabular}{|c|c|c|c|}
\hline & $\begin{array}{l}\text { Hibernia } \\
\text { Dec 2005-2010 }\end{array}$ & $\begin{array}{l}\text { Terra Nova } \\
2005^{-2010}\end{array}$ & $\begin{array}{l}\text { White Rose } \\
2006-2010^{d}\end{array}$ \\
\hline Number of entries ${ }^{c}$ & $5^{0}$ & 134 & 100 \\
\hline $\begin{array}{l}\text { Do the entries have dates for } \\
\text { birds found? }\end{array}$ & $48 / 5^{0}$ & $134 / 134$ & $86 / 100^{d}$ \\
\hline $\begin{array}{l}\text { Do the entries provide the } \\
\text { weather conditions when a } \\
\text { bird(s) was found? }{ }^{\text {a }}\end{array}$ & $\begin{array}{l}\text { No } \\
(0 / 50)\end{array}$ & $\begin{array}{l}\text { No } \\
(0 / 134)\end{array}$ & $\begin{array}{l}\text { No } \\
(0 / 100)\end{array}$ \\
\hline $\begin{array}{l}\text { Do the entries provide the fate of } \\
\text { each bird?a }\end{array}$ & $\begin{array}{l}\text { Yes } \\
(49 / 50)\end{array}$ & $\begin{array}{l}\text { Yes } \\
(134 / 134)\end{array}$ & $\begin{array}{l}\text { Yes } \\
(100 / 100)\end{array}$ \\
\hline $\begin{array}{l}\text { Do the entries have the number } \\
\text { of birds found? }\end{array}$ & $\begin{array}{l}\text { Yes } \\
(48 / 50)\end{array}$ & $\begin{array}{l}\text { Yes } \\
(134 / 134)\end{array}$ & $\begin{array}{l}\text { Yes } \\
(100 / 100)\end{array}$ \\
\hline $\begin{array}{l}\text { Do the entries have a start and } \\
\text { stop time of when searches } \\
\text { occurred?b }\end{array}$ & $\begin{array}{l}\text { No } \\
(0 / 50)\end{array}$ & $\begin{array}{l}\text { No } \\
(0 / 134)\end{array}$ & $\begin{array}{l}\text { No } \\
(0 / 100)\end{array}$ \\
\hline $\begin{array}{l}\text { Do the entries indicate where } \\
\text { the searches occurred on the } \\
\text { platform? }\end{array}$ & $\begin{array}{l}\text { No } \\
(0 / 50)\end{array}$ & $\begin{array}{l}\text { No } \\
(0 / 134)\end{array}$ & $\begin{array}{l}\text { No } \\
(0 / 100)\end{array}$ \\
\hline $\begin{array}{l}\text { Are there negative entries (i.e., } \\
\text { searched but no birds found)? }\end{array}$ & $\begin{array}{l}\text { No } \\
(0 / 50)\end{array}$ & $\begin{array}{l}\text { No } \\
(0 / 134)\end{array}$ & $\begin{array}{l}\text { No } \\
(0 / 100)\end{array}$ \\
\hline
\end{tabular}

a Williams and Chardine 2005, n. 38 above.

b Baillie et al. 2005, n. 44 above.

c An entry was not equivalent to the number of birds. The range for the number of birds found per entry was from 1-81 (Hibernia), 1-22 (Terra Nova) and 1-75 (White Rose).

d 2009 data were summarized by month with no day.

bird was found dead, occasionally comments were provided, which indicated how it was thought to have died (e.g., collision). The reports from production platforms confirmed that operators did not implement Environment Canada's recommendations for a systematic monitoring program. Specifically, there was no start and stop time, no indication of the area searched, nor operator reports of negative entries (Table 10.1), or even the time and weather conditions as requested in the protocol (but not queried on the form). 
In the 2010 Hebron EA, the Canadian Wildlife Service again noted the lack of information on seabird attraction and expressed the need for systematic monitoring to occur to understand the mechanisms of seabird attraction. Specifically, as part of the EA review, they requested data collection on meteorological and operational conditions (e.g., flares) at the time of bird strandings. Environment Canada also disagreed with the proponent's proposal that seabird monitoring would not be part of the environmental effects monitoring program and specifically mentioned the EA predictions for seabird attraction. ${ }^{49}$

\section{The C-NLOPB}

From 1997 to 2017, in both the EA and post-EA (environmental effects monitoring period) processes, the C-NLOPB showed resistance to implement Environment Canada's expert advice, while simultaneously proclaiming a precautionary principle approach for their decisions. ${ }^{50}$ Two lines of evidence support our argument. First, the C-NLOPB repeatedly rejected calls for observers to collect seabird monitoring data from production platforms. ${ }^{51}$ The Terra Nova Review Panel recommended the use of independent observers. ${ }^{52}$ Environment Canada and the Commissioner's review for the White Rose Project also recommended the placement of a qualified observer on the production

49 Comments on Hebron Project Comprehensive Study Review, Information Response \#1 Part 1, comment 129, EC, 46, p. 7, January 17, 2011, File no. 4572-10, available online: <http:// www.cnlopb.ca/assessments/hebron.php >; see also Fraser and Russell, n. 37 above.

5o The Board has underscored that, "in all of its decisions respecting approval of activities in the Newfoundland Offshore Area, it has adopted an approach which is consistent with the definition of the precautionary principle enunciated in Principle 16 [sic] of the Rio Declaration on Environment and Development" (C-NOPB, n. 36 above); see also C-NOPB, Decision Report 2001.01 Application for Approval, White Rose Canada-Newfoundland Benefits Plan, White Rose Development Plan (St. John's: C-NOPB, November 16, 2001), p. 133.

$5^{1} \quad$ Independent observers could do a wide range of environmental monitoring tasks as well as collect data on seabird attraction to artificial light. For example, see G.S. Fraser and V. Racine, "An evaluation of oil spill responses for offshore oil production projects in Newfoundland and Labrador, Canada: Implications for seabird conservation," Marine Pollution Bulletin, 107, no. 1 (2016): 36-45.

52 Terra Nova Development Project Environmental Assessment Panel, A Report to the Canadian Environmental Assessment Agency, Canada-Newfoundland Offshore Petroleum Board and The Government of Newfoundland and Labrador (St. John's: Terra Nova Development Project Environmental Assessment Panel Report, August 1997), Recommendation 67. 
facility. ${ }^{53}$ The C-NLOPB argued that industry personnel could collect "valid and credible" data and that they would monitor the situation. ${ }^{54}$ Yet, no action was taken to move toward independent observers when it was clear valid data collection was not achievable the first year after the issuance of migratory bird salvage permits for each project. The need for independent observers has been repeatedly identified specifically for this region in the scientific literature as a solution to resolve the paucity, and to improve the quality, of data on seabird interactions with platforms. ${ }^{55}$

In 2001, the Commissioner for the White Rose Project recommended that the seabird attraction issue be studied. ${ }^{56}$ The C-NLOPB identified that the Environmental Studies Research Funds (ESRF) would be used for general seabird research, instead of requiring the operator to include seabird attraction to artificial light in their environmental effects monitoring program. ${ }^{57}$ The ESRF funding for seabird attraction was only available for one year (2002). Thus, the C-NLOPB did not ensure that experimental research was conducted to assist in identifying attraction mechanism(s), ${ }^{58}$ despite the EA prediction(s) having been rated with high or medium uncertainty. Fraser and Russell argued that given the high prediction uncertainty, seabird attraction should have been included in the White Rose environmental monitoring effects program. ${ }^{59}$

53 H.M. Clarke, Report of the Public Review Commissioner for the White Rose Development Application (St. John's: C-NOPB, 2001). Environment Canada had identified the need for a monitoring program during the White Rose EA (Recommendation 189, Husky Oil Operations Ltd., White Rose Comprehensive Study Supplemental Report, (St. John's: Husky Oil, April 2001, p. 240) and also recommended trained observers to ensure systematic data collection (Baillie et al., n. 44 above).

54 C-NLOPB stated that "valid and credible seabird observation data can result from the use of industry personnel or their contractors, provided that those personnel are properly trained and that conduct of observations forms part of their core duties" and that they would "monitor these portions of the Proponent's program and to consider alternatives to that program should it be found to be deficient." C-NOPB, 2001, n. 50 above, p. 133 .

55 Wiese et al., n.7 above; C.M. Burke et al., "Seasonal and spatial trends of marine birds along support vessel transects and at oil platforms on the Grand Banks," in Offshore Oil and Gas Environmental Effects Monitoring, Approaches and Technologies, eds. S.L. Armsworthy et al. (Columbus: Battelle Press, 2005), pp. 587-614; Burke et al., n. 9 above; Ronconi et al., n. 9 above; Fraser and Racine, n. 51 above.

56 Clarke, $n .53$ above.

57 The C-NLOPB stated, "general research into effects of offshore petroleum operations upon seabirds is best approached through the Environmental Studies Research Funds (ESRF)." C-NOPB 2001, n. 50 above, p. 132.

58 C-NLOPB 2001, id., p. 133; Fraser and Russell, n. 37 above.

59 Fraser and Russell, id. 
A follow-up program would have helped implement a systematic monitoring program and directly address Environment Canada's recommendations. ${ }^{60}$

The Commissioner reviewing the Hebron project (the most recent production project) recommended that the C-NLOPB incorporate a seabird attraction study under an environmental effects monitoring program. In response, the C-NLOPB stated that they were "prepared to consider the research as part of the Proponent's environmental effects monitoring (EEM) program, albeit as a feasibility study component of EEM until its efficacy becomes clear." However, in their final recommendation, they did not specifically identify seabird attraction study requirements under the EEM program and in the draft EEM seabird attraction was not included. ${ }^{61}$

In summary, all three operators have implemented the protocol. But the protocol established a very low bar: it does not permit any serious investigation of seabird attraction to artificial light, it does not permit the discovery, let alone the implementation, of appropriate mitigation measures, and it does not permit informed decision-making for subsequent EAs. Information from the protocol is inadequate as it cannot verify the EA prediction using measures of magnitude, geographic extent, frequency, duration, and reversibility. Environmental Canada has urged the operators to improve data collection by using systematic monitoring approaches, but the C-NLOPB has ignored and rebuffed these recommendations until recently, where it provided a lukewarm commitment to engage. ${ }^{62}$

\section{Conclusion}

This study underlines longstanding and continued gaps in the regulation of the impacts of artificial lighting from offshore oil production operations on seabirds and demonstrates that the C-NLOPB is not following through on its commitment of environmental protection. Had it done so, we would have a much clearer understanding of the level of risk artificial light poses to certain seabird populations, which could have informed subsequent production projects. This problem is now urgent given ongoing declines in seabird species, particularly species most at risk from artificial light (e.g., Leach's storm petrel

6o Canadian Environmental Assessment Act, n. 17 above, s. 38; see also Fraser and Russell, id.

61 C-NLOPB, Staff Analysis Hebron Development Plan (St. John's: C-NLOPB, April 2012), p. 27; Exxon Mobil, "Exxon Mobil summary of design of the Hebron offshore Environmental Effects Monitoring program” (St. John's ExxonMobil Canada Ltd, May 2017). Id. 
is now "vulnerable" on the IUCN Red List and has shown a regional decline in $\mathrm{NL}) .{ }^{63} \mathrm{An}$ appropriate regulatory approach would be to require all production operators to immediately undertake basic mitigation efforts, such as adopting light deflectors ${ }^{64}$ (an action recommended by Environment Canada in 1997 ${ }^{65}$ ), and to immediately implement a robust monitoring program, undertaken by independent observers and overseen by Environment Canada. Once independent observers are placed, the timing and length of flaring activities, along with the bird stranding events, should be reported to the public by the C-NLOPB and Environment Canada on a regular basis.

This study also points to fundamental problems with the existing environmental governance structure around NL's offshore oil industry. First, this case demonstrated the limits of the MOU that was intended to provide a governance structure to ensure cooperation between Environment Canada and the C-NLOPB. MOUs are often used to solve jurisdictional quandaries that arise over environmental issues: they clarify the implementation of legislation or agreements by delineating power and responsibility. ${ }^{66}$ But in this case, the C-NLOPB failed to fully implement Environment Canada's recommendations and was not in compliance for the provision of environmental services. The C-NLOPB and Environment Canada did not cooperate; rather, Environment Canada appears to have occupied a subordinate position to the Board. Given the wording of the updated MOU in 2015, ${ }^{67}$ these issues are unlikely to have been resolved. Second, this case provides evidence that the devolution of environmental regulatory authority to the C-NLOPB places seabirds at risk. Twenty years after the risk of seabird attraction to artificial light from offshore oil and gas installations was identified, ${ }^{68}$ artificial light is not yet a regulated pollutant with an associated set of guidelines. This raises, yet again, concerns about the

63 IUCN Red List of Endangered Species, Hydrobates leucorhous, available online: <http:// www.iucnredlist.org/details/22698511/o>; see also S.I. Wilhelm et al., "Update and trends of three important seabird populations in the western North Atlantic using a geographic information system approach," Marine Ornithology 43 (2015): 211-222.

64 J.R. Reed et al., "Light attraction in endangered Procellariiform birds: Reduction by shielding upward radiation," Auk 102, no. 2 (1985): 377-383; H. Poot et al., "Green light for nocturnally migrating birds," Ecology and Society 13, no. 2 (2008): 47-61; W. Miles et al., "Effects of artificial lights and moonlight on petrels at St. Kilda," Bird Study 57 (2010): 244-251.

65 Environment Canada 1996, n. 35 above, Recommendation 25.

66 D. McCrimmon and L. Fanning, "Using memoranda of understanding to facilitate marine management in Canada," Marine Policy 34, no. 6 (2010): 1335-1340.

$67 \quad$ C-NLOPB et al. 2015, n. 19 above.

68 Petro-Canada, n. 23 above. 
C-NLOPB's capacity or willingness to undertake environmental regulation ${ }^{69}$ and points to the Board's conflict of interest (as is the case with human health ${ }^{70}$ given its responsibility for ensuring both environmental protection and economic benefits from oil development. ${ }^{71}$ Finally, and most broadly, this study highlights how the Atlantic Accord Act, ${ }^{72}$ conceived primarily to ensure revenue sharing from offshore oil development, is inherently weak when applied to environmental issues. ${ }^{73} \mathrm{~A}$ new environmental regulatory structure is required, one that can ensure environmental review and protection that is independent from revenue, development concerns, and industry interests.

69 Fraser and Russell, n. 37 above; G.S. Fraser and J. Ellis, "Offshore hydrocarbon and synthetic hydrocarbon spills in eastern Canada: The issue of follow-up and experience," Journal of Environmental Assessment Policy and Management 10, no. 2 (2008): 173-187; A. Carter et al., "Environmental policy convergence in Canada's fossil fuel provinces? Regulatory streamlining, impediments, and drift," Canadian Public Policy 43 (2017): doi: http://dx.doi .org/10.3138/cpp.2016-041.

$70 \quad$ R. Wells, Offshore Helicopter Safety Inquiry Volume 1, Report and Recommendations (St. John's: C-NLOPB, October 2010).

71 The priorities of the C-NLOPB are perhaps best reflected in the composition of the Board: the seven members are primarily drawn from industry and government with limited environmental expertise. Concern about lack of environmental expertise among Board members was noted in the 2012 audit by the Office of the Auditor General of Canada. See "Chapter 1: Atlantic Offshore Oil and Gas Activities," in Report of the Commissioner of the Environment and Sustainable Development (Ottawa: Government of Canada, 2012).

72 Atlantic Accord Act, n. 14 above.

73 G.S. Fraser and J. Ellis, "The Canada-Newfoundland Atlantic Accord Implementation Act: Transparency of the environmental management of the offshore oil and gas industry," Marine Policy 33, no. 2 (2008): 312-316. 